\title{
KAJIAN KINERJA PELAYANAN TERMINAL ANGKUTAN UMUM (STUDI KASUS TERMINAL BECORA DILI - TIMOR LESTE)
}

\author{
The Study of Terminal Performance Service of Public Transportation (Case Study Becora \\ Terminal Dili-East Timor)
}

\author{
Nelson Francisco A.D.S.Silva ${ }^{1}$, Harnen Sulistio ${ }^{2}$, Sobri Abusini ${ }^{3}$ \\ 1,2,3 Jurusan Teknik Sipil, Fakultas Teknik Universitas Brawijaya \\ Alamat korespondensi : Jln. MT. Haryono, No 167 Malang \\ e-mail: joshbar09@gmail.com
}

\begin{abstract}
Public transportation terminal constitute of transportation node that function as a place of passenger transit to the other mode of transportation. The study was conducted at Becora terminal in period of time shown less optimum performance services and poor facility condition as standardized for a type B terminal. The objective of study was to find out factors influencing operational performance in Becora terminal, to make recommendation by increasing terminal performance regarding to terminal customer service and also the formula regression model the correlation between quality service and influential variables. Data analysis to be down by importance performance analysis (IPA) methods and quality funcitional deploymen(QFD) methods, also regression analysis to create predictable model and simulation of influential correlation between service variable to quality service. The result of IPA analysis shown 14 attributes of services stayed in I quadran wich become to principal priority of rehabilitation, whereas the QFD shown 8 technical response collected for rehabilitation attribute of service. Model to be obtained by multiple linear regression analysis were $Y=-0,328+0.276 X_{3}$ with value $R^{2}=0.274$ so that comfortable variables $\left(X_{3}\right)$ become influential variables $72.4 \%$ regarding to quality service.
\end{abstract}

Keywords: Terminal, IPA analysis, QFD Analysis

\begin{abstract}
Abstrak
Terminal angkutan umum merupakan salah satu simpul transportasi yang berfungsi sebagai tempat transit penumpang untuk beralih ke moda angkutan umum lain. Kajian dilakukan pada Terminal Becora yang pada saat ini kinerja Pelayanannya kurang optimal dan kondisi fasilitas pelayanan terminal yang masih sangat minim dari yang distandarkan oleh suatu terminal tipe B. Tujuan pada penelitian ini adalah untuk mengetahui faktor-faktor yang mempengaruhi kinerja operasional terminal Becora, membuat rekomendasi guna meningkatan kinerja Terminal terhadap kepuasaan pengguna jasa terminal serta membuat model regresi hubungan antara kualitas pelayanan dan variabel yang mempengaruhinya. Analisa data dilakukan dengan metode IPA (importance performance analysis) dan metode quality funcitional deployment $(Q F D)$ serta analisa regresi untuk membuat model prediksi dan simulasi pengaruh hubungan yang terjadi antara variabel pelayanan dengan kualitas pelayanan. Hasil analisa IPA menunjukkan 14 atribut pelayanan berada di kuadran I yang menjadi prioritas utama perbaikan, sedangkan pada analisa quality functional deployment $(Q F D)$ didapatkan 8 respon teknis yang dapat dilakukan untuk perbaikan atribut-atribut pelayanan tersebut. Model yang didapatkan dari analisa regresi linear berganda yaitu: $Y_{=}-\mathbf{0 . 3 2 8 + 0 . 2 7 6} X_{3}$ dengan nilai $R^{2}=0.724$, sehingga variabel kenyamanan $\left(\mathrm{X}_{3}\right)$ menjadi variabel yang berpengaruh sebesar $72.4 \%$ terhadap kualitas pelayanan $(\mathrm{Y})$.
\end{abstract}

Kata Kunci: Terminal, Analysis IPA, Analisis QFD.

\section{PENDAHULUAN}

Terminal angkutan umum merupakan salah satu simpul transportasi yang berfungsi sebagai tempat transit penumpang untuk beralih ke moda angkutan umum lain. Terminal sebagai salah satu prasarana pelayanan umum tentunya perlu didukung dengan fasilitas pelayanan dan jasa pelayanan yang optimal sehingga kinerja pelayanan terminal dapat terwujud.

Terminal Becora merupakan salah satu terminal tipe B yang dibangun pada tahun 1990an 
yang terletak Sub distritu Cristo Rei, Distritu DiliTimor Leste, sebagai titik simpul pergantian moda transportasi penumpang angkutan umum baik yang bergerak menuju kota Dili maupun yang meninggalkan kota Dili. Sebagai terminal kategori tipe B dalam proses pelayanan terhadap user masih jauh seperti yang diharapkan atau yang distandarkan pada terminal tipe B. Minimnya fasilitas utama dan fasilitas penunjang kelengkapan terminal sebagaimana yang dipersyaratkan oleh suatu terminal seperti ruang tunggu penumpang, fasilitas kamar mandi dan toilet, tempat makan, loket tiket, kios, gate kedatangan dan keberangkatan, tempat parkir dan fasilitas lainya masih belum optimal. Pada areal parkir angkutan umum tidak tertata dengan baik sehingga timbul kesemerawutan pada pintu masuk dan keluar terminal, sehingga menyebabkan kemacetan jalan disekitar terminal Becora pada waktu jam-jam puncak.

Hal tersebut dikarenakan kapasitas terminal yang dulu direncanakan hanya untuk volume kenderaan yang kecil, tetapi dengan adanya perubahan wilayah administrasi yang sekarang terpusat di kota Dili menyebabkan volume kenderaan meningkat dengan pesat tetapi tidak diimbangi dengan perbaikan sarana dan prasarana transportasi.

Kondisi tersebut menyebabkan kinerja terminal Becora kurang optimal dalam memberikan pelayanan kepada user sehingga sangat diperlukan suatu perbaikan dan pengelolaan yang baik agar kriteria terminal sebagai simpul transportasi dapat memberikan pelayanan yang aman, nyaman dan lancar bagi pengguna jasa.

Tujuan yang hendak dicapai pada penelitian ini adalah sebagai berikut:

- Mengetahui faktor-faktor yang mempengaruhi kinerja operasional terminal Becora.

- Membuat rekomendasi guna meningkatan kinerja Terminal terhadap kepuasaan pengguna jasa terminal yaitu penumpang angkutan umum.

- Membuat model prediksi terkait kepuasaan pengguna jasa.

Referensi kajian berdasarkan Undang-Undang RI No.14 Tahun 1992 dan Keputusan Menteri Perhubungan RI No.31 Tahun 1995. Kajian-kajian terdahulu tentang terminal yang dijadikan referensi pada penelitian ini antara lain: Pemodelan pelayanan terminal penumpang transportasi jalan berbasis kepuasaan pengguna (Agung Sedayu, 2013). Penelitian lain yang dilakukan dalam memberikan jasa pelayanan yang baik kepada pelanggan, terdapat lima Kriteria penentu kualitas jasa pelayanan yaitu: keandalan, responsif, keyakinan, empati serta berwujud. Adanya lima dimensi jasa pelayanan tersebut merupakan kriteria dalam menilai kualitas atas sebuah jasa pelayanan sehingga konsumen akan merasa puas atas jasa pelayanan seperti yang diharapkan (Rahman 2009).

\section{METODE PENELITIAN}

Kajian kinerja pelayanan terminal dilakukan untuk mengetahui seberapa besar pelayanan yang diberikan suatu terminal terhadap pengguna jasa terminal, yang berbasis pada kepuasaan yang dirasakan. Lokasi kajian adalah terminal Becora Sub distritu Cristo Rei, Distritu Dili- Timor Leste.

\section{Sampel Kajian}

Kajian dilakukan terhadap 100 orang responden penumpang angkutan umum yang ada di terminal Becora. Sampel kajian menggunakan teknik random sampling berdasarkan rumus Slovin yaitu:

$$
n=\frac{N}{1+N e^{2}}
$$

Pers 1.

$$
N=\frac{266236}{1+266236(0.10)^{2}}
$$

$N=99.962$ H” 100

\section{Keterangan:}

$\mathrm{n}=$ ukuran sampel

$\mathrm{N}=$ ukuran populasi

$\mathrm{E}=$ presisi yang digunakan (diambil 10\%-20\%)

Teknik dalam pengumpulan data berupa data primer dan data sekunder. Pengumpulan data primer dilakukan di terminal Becora berupa dokumentasi, wawancara serta survey kuisioner yang berbasis kepada kepuasaan pengguna terhadap variabelvariabel kajian. Data sekunder didasarkan pada studi-studi kajian terdahulu dan literatur berupa jurnal dan internet. 
Banyak penelitian yang sudah dilakukan dengan menggunakan variabel-variabel yang berhubungan dan berpengaruh terhadap kinerja pelayanan.

Tabel 1. Atribut Pelayanan Pada Kajian Terminal Becora

\begin{tabular}{|c|c|c|c|}
\hline Notasi & Atribut Pelayanan & Notasi & Atribut Pelayanan \\
\hline & Kamar Mandi dan Toilet Berfungsi dengan & & \\
\hline AT-1 & Baik & AT-23 & Kemudahan mendapatkan fasilitas pelayanan \\
\hline AT-2 & Kondisi jalan dlm terminal baik & AT-24 & Kepadatan pengunjung dalam terminal \\
\hline AT-3 & Kondisi tempat parkir baik & AT-25 & Terjadi kemacetan arus kendaraan \\
\hline AT -4 & Kondisi pencahayaan yang baik & AT-26 & Penambahan jumlah kamar mandi dan toilet \\
\hline AT-5 & Kondisi penghawaan & AT-27 & Penambahan tempat duduk \\
\hline AT-6 & Kedatangan dan keberangkatan tepat waktu & AT-28 & Penambahan Jumlah petugas \\
\hline AT-7 & Waktu tunggu yang tidak lama & AT-29 & Tersedianya tempat parkir yang memadai \\
\hline AT-8 & Daya tahan fasilitas-fasilitas pelayanan & AT-30 & Tersedianya ruang tunggu yang memadai \\
\hline AT-9 & Masa pelayanan fasilitas & AT-31 & Tersedianya fasilitas kios yang memadai \\
\hline AT-10 & Pertolongan kesehatan & AT-32 & Tersedianya fasilitas persampahan \\
\hline AT-11 & Jadwal keberangkatan yang tepat & AT-33 & Tersedianya fasilitas penginapan \\
\hline AT-12 & Perlindungan dan keselamatan & AT-34 & Tersedianya kantin dan tempat makan \\
\hline AT-13 & $\begin{array}{l}\text { Petugas yang tanggap atas permasalahan } \\
\text { pelanggan }\end{array}$ & AT-35 & Tersedianya papan informasi perjalanan \\
\hline AT-14 & $\begin{array}{l}\text { Petugas yang bijak dalam mengatur jam } \\
\text { pemberangkatan }\end{array}$ & AT-36 & Tersedianya pos informasi \\
\hline AT-15 & Petugas yang sopan dan ramah & AT-37 & Tersedianya tempat penitipan barang \\
\hline AT-16 & $\begin{array}{l}\text { Kenyamanan dalam ruang tunggu (cuaca } \\
\text { atau hawa) }\end{array}$ & AT-38 & Tersedianya papan tariff trayek \\
\hline AT-17 & Terbebas dari panas dan debu & AT-39 & Tersedianya toilet kamar mandi yang bersih \\
\hline AT-18 & Kebersihan dalam ruangan & AT -40 & Tersedianya fasilitas ibadah \\
\hline AT-19 & Sirkulasi dan keteraturan tatanan parkir & AT-41 & $\begin{array}{l}\text { Adanya fasilitas telekomunikasi (wartel), } \\
\text { warnet atau TV }\end{array}$ \\
\hline AT-20 & Jalur masuk dan keluar kendaraan & AT-42 & Tersedianya loket agen perjalanan \\
\hline AT-21 & Kemudahaan dalam mendapatkan informasi & AT-43 & Adanya pos kesehatan \\
\hline AT-22 & Kemudahaan dalam mendapatkan angkutan & AT-44 & $\begin{array}{l}\text { Tersedianya fasilitas bank, ATM, dan money } \\
\text { changer }\end{array}$ \\
\hline
\end{tabular}

Variabel tersebut perlu ditambahkan variable lain atau dikembangkan apabila didapatkan masukan dan keinginan dari user. Pada kajian ini dipakai atribut-atribut yang mempunyai pengaruh terhadap kinerja operasional terminal Becora dan atribut tambahan lain yang dapat dilihat pada Tabel 1. . Variabel dan atribut pelayanan tersebut disusun dalam bentuk kuisioner kemudian disebarkan kepada responden. Bobot penilaian menggunakan skala linkert dimulai dari intensitas paling rendah sampai intensitas paling tinggi dapat dilihat pada Table 2.

Tabel 2. Bobot Penilaian

\begin{tabular}{ccc}
\hline Nilai / & \multicolumn{2}{c}{ Jawaban } \\
\cline { 2 - 3 } bobot & Kepuasaan & Kepentingan \\
\hline 5 & Sangat puas & Sangat Penting \\
4 & Puas & Penting \\
3 & Cukup Puas & Cukup Penting \\
2 & Kurang Puas & Kurang Penting \\
1 & Tidak Puas & Tidak Penting \\
\hline
\end{tabular}

Data hasil survey kuisioner tersebut kemudian diolah dan dianalisis dengan menggunakan beberapa metode antara lain:

\section{Metode importance Performance Analysis (IPA)}

Metode importance Performance Analysis (IPA) digunakan untuk mengukur kepuasaan pengguna jasa (user) terhadap atribut-atribut pelayanan guna meningkatkan suatu kualitas jasa. Metode tersebut dilakukan dengan menentukkan nilai tingkat kesesuaian dari penilaian tingkat kepuasaan dan kepentingan kedalam grafik yang searah dengan sumbu $\mathrm{X}$ dan $\mathrm{Y}$ yang disebut diagram kartesius.

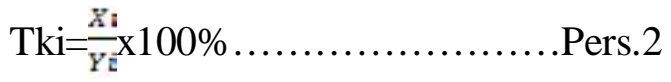


Hasil penilaian dapat memberikan informasi tentang atribut-atribut pelayanan yang mempengaruhi kepuasaan konsumen terhadap suatu produk/jasa dengan melakukan prioritas perbaikan. Berikut penjelasan mengenai diagram kartesius keempat kuadran yang ada pada Gambar 1 .

- Kuadran pertama (Prioritas utama)

- Pada kuadran ini memuat faktor-faktor yang dianggap penting oleh pelanggan tetapi pada kenyataannya faktor-faktor ini belum sesuai seperti yang diharapkan, dimana (tingkat kepuasan yang diperoleh masih sangat rendah). Pada kuadran ini harus dilakukan perbaikan agar dapat meningkatkan performance dalam kuadran ini.

- $\quad$ Kuadran kedua (Pertahankan prestasi)

- $\quad$ Pada kuadran ini memuat faktor-faktor yang dianggap penting oleh pengguna jasa (user) dan faktor-faktor yang diangap oleh pengguna jasa sudah sesuai dengan yang dirasakanya sehingga tingkat kepuasaanya lebih tinggi.

- Kuadran ketiga (Prioritas rendah)

- $\quad$ Pada kuadran ini faktor-faktor yang dianggap kurang penting oleh pengguna jasa (user) dan pada kenyataanya kinerjanya tidak terlalu istimewa.

- Kuadran keempat (Berlebihan)

- Pada kuadran ini memuat faktor-faktor yang dianggap kurang penting yang oleh pengguna jasa dan dirasakan terlalu berlebihan.

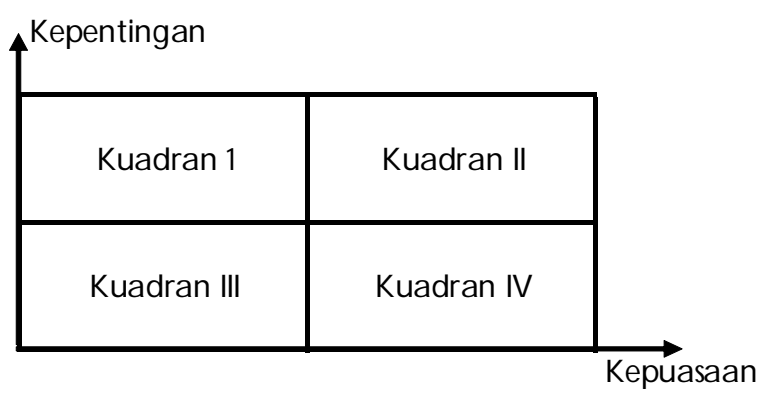

Gambar 1. Diagram Kartesius

\section{Metode Quality Function Deployment (QFD)}

Metode quality function deployment (QFD) merupakan konversi kebutuhan pelanggan yang secara teknis ke dalam suatu produk/jasa untuk merealisasikan hubungan kebutuhan pelanggan secara sistematis dan berkualitas (yamamoto 2005). Tahap awal dari quality function deployment adalah dengan mengetahui suara dari pelanggan atau Voice Of Costumer (VOC), selanjutnya penentuan karakteristik teknik kemudian dilanjutkan dengan pembuatan House Of Quality (HOQ) atau rumah kualitas. Untuk proses pembentukan HOQ dapat dilihat pada Gambar 2.

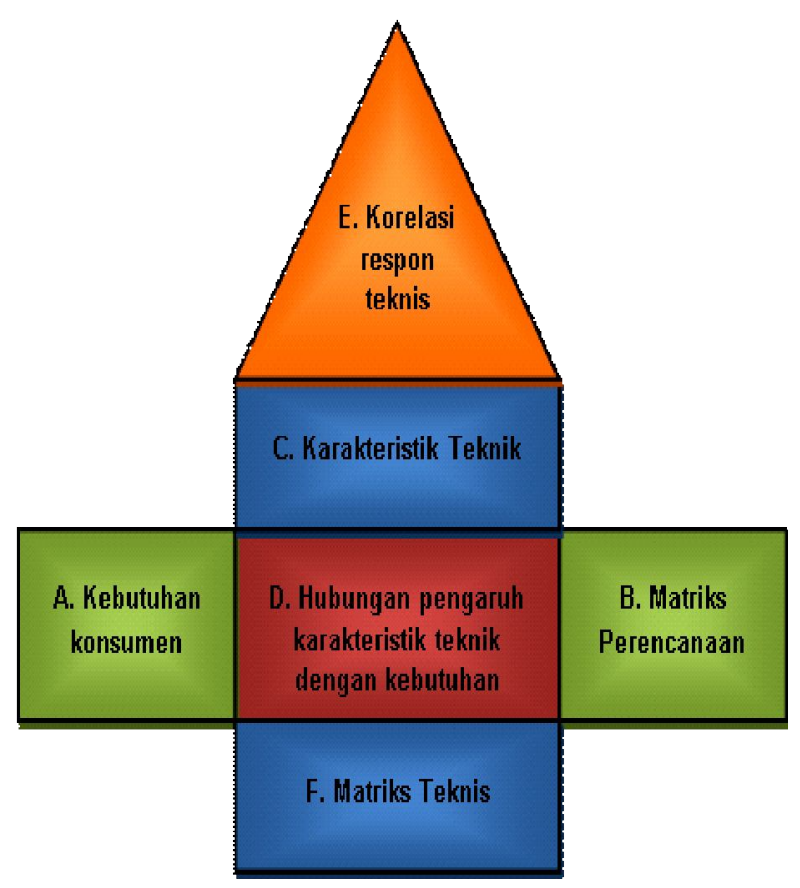

Gambar 2 Rumah Kualitas (Sumber I.B Suryaningrat, 2010) Langkah - langkah dalam membuat house of quality :

- Voice of Costumer

- Voice of Costumer atau suara pelanggan merupakan tahap awal yang didapat dari hasil pengumpulan wawancara dan kuisioner dari beberapa pengguna jasa.

- Planning Matrix

- Ada beberapa langkah yang dilakukan dalam matrix perencanaan antara lain:

- Importance to Customer (ItC) : Pada langkah ini mengukur tingkat kepentingan yang didapatkan dari pengguna jasa.

- Customer Satisfaction Performance (CSP)

- Penilaian ini didapatkan dari presepsi pengguna jasa terhadap tingkat pelayanan yang didapatkan. Rumus yang digunakan:

CSP $=\frac{\text { Total Kebutuhan } X}{\text { Jumlah Responden }}$ Pers 3 
- Goal

Nilai Goal menunjukan seberapa besar keinginan dan sasaran yang ingin dicapai dalam memenuhi kebutuhan pengguna..

\section{- Improvement Ratio}

Improvement Ratio menunjukkan seberapa besar usaha yang dilakukan untuk memperbaiki dan meningkatkan kualitas pelayanan agar sesuai harapan dan keinginan dari pengguna jasa. Persamaan yang digunakan adalah:

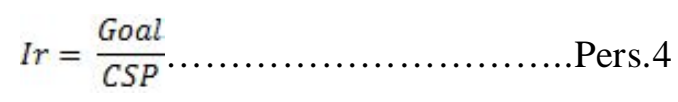

- $\quad$ Sales Point

Sales point merupakan informasi kemampuan menjual produk/jasa berdasarkan seberapa baik setiap kebutuhan pelanggan terpenuhi.

Tabel 3 Nilai Sales Point

\begin{tabular}{cc}
\hline Nilai & Keterangan \\
\hline 1 & Tidak ada penjualan \\
1,2 & Penjualan sedang \\
1,5 & Penjualan kuat \\
\hline
\end{tabular}

- Raw Weight and Normalized Raw weight

Raw weight merupakan model yang didapatkan dari kepentingan pengelola terhadap setiap kebutuhan pelanggan yang didasarkan pada nilai dari ITC, IR yang harus dilakukan dan sales point yang telah ditentukan. Persamaannya :

$R W=$ Goal $\times$ IR x Sales Point.........Pers. 5

Nomalized Raw Weight didapatkan dengan mengkonversikan nilai Raw weight ke dalam presentase dimana nilai Normalized Raw Weight akan sama dengan 1 . Persamaan yang digunakan adalah:

$$
N R W=\frac{\text { Raw Weight }}{\text { Total } \text { Raw Weight }} \ldots \ldots \ldots \ldots \ldots . . \text { Pers.6 }
$$

- Respon Teknis

Hasil penilaian yang didapat tersebut menjadi masukan kemudian mencari solusi perbaikan atau penangan dari segi teknis yang disesuaikan dengan masukan dan harapan dari pengguna jasa.

\section{- Relationship Matrix}

Relationship matrix perlu dilakukan untuk mengetahui sejauh mana respon teknis tersebut dapat memenuhi kebutuhan pelanggan. Hubungan ini digambarkan dengan simbol-simbol yan dapat dilihat pada Tabel 4

Tabel 4. Nilai Relationship Matrix

\begin{tabular}{ccc}
\hline Simbol & Nilai & Keterangan \\
\hline Kosong & 0 & Tidak ada hubungan \\
$\Delta$ & 1 & Hubungan lemah \\
o & 3 & Hubungan sedang \\
$\odot$ & 9 & Sangat kuat hubungannya \\
\hline
\end{tabular}

\section{- Technical Corelation}

Technical Corelation perlu dibuat untuk memetakan hubungan dan ketergantungan antar tim respon teknis. Hubungan tersebut digambarkan dalam simbol dapat dilihat pada Tabel 5 .

Tabel 5 Arti Simbol Korelasi

\begin{tabular}{cc}
\hline Simbol & Arti \\
\hline$\sqrt{ }$ & Pengaruh positif sangat kuat \\
+ & Pengaruh Positif cukup kuat \\
$<$ Kosong $>$ & Tidak ada pengaruh \\
- & Pengaruh negative cukup kuat \\
$\mathbf{X}$ & Pengaruh negative sangat kuat \\
\hline
\end{tabular}

- Benchmarking dan Penetapan Target.

Nilai dalam benchmarking ini merupakan nilai-nilai performansi respon teknis untuk meningkatkan mutu dan kualitas pelayanan, kemudian merencanakan dengan tepat target yang ingin dicapai untuk memenuhi kebutuhan pelanggan. Nilai-Nilai tersebut antara lain:

- Contribution

Contribution $=$ ÓNRW $\mathrm{x}$ Nilai Numerik hubungan Matriks Pers. 7

- own Performance

$$
O P=\frac{\sum C S P}{\sum N V} \ldots \ldots \ldots \ldots \ldots \ldots \ldots \ldots \text { Pers } 8
$$

Dimana :

$\mathrm{OP}=$ Own Performance

$\mathrm{NV}=$ Numerical Value

$\mathrm{CSP}=$ Customer Satisfaction Performance 


\section{Analisis Regresi Linear Berganda}

Regresi linear berganda merupakan metode statistik yang bertujuan untuk melihat hubungan antara variabel tidak bebas dengan dua atau lebih variabel bebas untuk meramal suatu variabel. Asumsi yang harus dipenuhi pada regresi ini yaitu tidak boleh ada korelasi kuat antara variabel-variabel bebas $(\mathrm{r}<$ $0.5)$.

Persamaan model regresi yang diusulkan adalah:

$\mathrm{Y}=\mathrm{a}+\mathrm{b}_{1} \mathrm{X}_{1}+\mathrm{b}_{2} \mathrm{X}_{2}+\mathrm{b}_{3} \mathrm{X}_{3}+$ bmXm.......Pers. 9

\section{HASIL DAN PEMBAHASAN}

\section{Analisa IPA}

Dari hasil perhitungan yang dilakukan terhadap 44 atribut pelayanan nilai rata-rata tingkat kepuasaan
$(X)=2.50$ dan nilai rata-rata tingkat kepentingan $(Y)=3.64$. Setelah dilakukan pengambaran maka dapat diketahui letak masing-masing atribut-atribut pelayanan pada kuadran IPA. Hasil yang didapatkan menunjukkan 14 atribut berada dalam kuadran I yang merupakan prioritas utama perbaikan. AtributAtribut tersebut antara Lain:

AT-1, AT-2, AT-3, AT-14, AT-16 AT-17, AT-18, AT-26, AT-27, AT-28, AT-29, AT-30, AT-32, dan AT-39. Untuk selengkapnya dapat dilihat pada Gambar 3.

\section{Analisa QFD}

Menentukan selisih atau gap dari nilai Tingkat kepentingan (TKP) dengan nilai dari tingkat kepuasaan yang dirasakan (TKS) yang dapat dilihat pada Gambar 4.

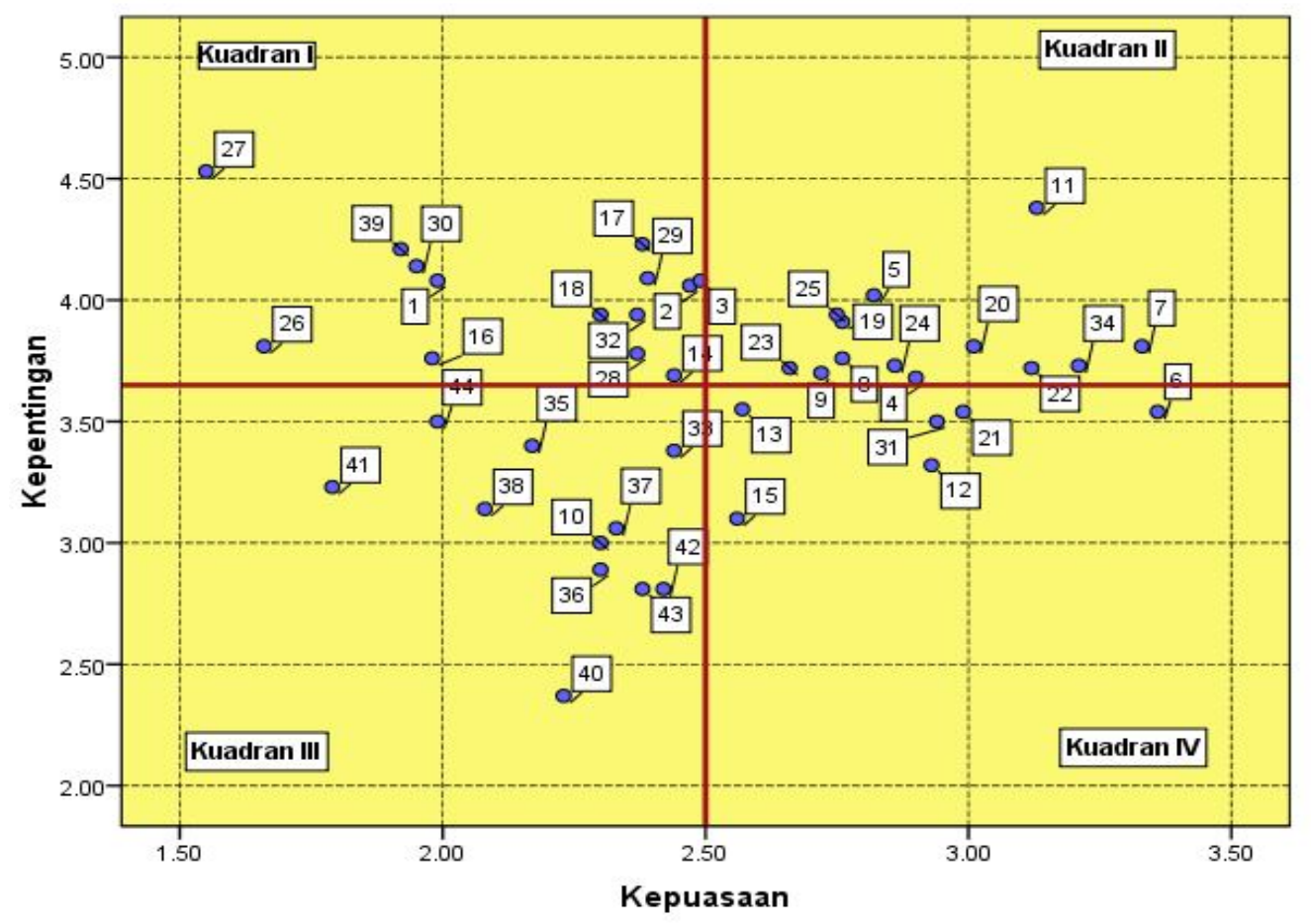

Gambar 3. Hasil Diagram Kartesius Terminal Becora

Hasil perhitungan TKP dengan TKS didapatkan Gap bernilai negatif yang artinya pelayanan yang didapatkan belum memuaskan pengguna jasa sehingga atribut-atribut tersebut perlu dilakukan upaya perbaikan. Nilai gap tersebut menjadi ukuran seberapa banyak permasalahan yang dihadapi pada Terminal Becora guna mencari solusi dan bentuk pemecahanya.

\section{Menentukkan parameter Perencanaan}

Langkah selanjutnya menentukkan parameter perencanaan dengan menyusun kebutuhan, kepentingan, kepuasaan dari pelanggan yang didapatkan dari voice of costumer dengan menentukkan nilai perbaikan dengan target yang ingin dicapai. Adapun tahap-tahap yang dilakukan 
untuk mendapatkan nilai-nilai tersebut antara lain: perhitungan nilai goal, perhitungan nilai improvement rasio, perhitungan nilai sales point, perhitungan nilai Raw Weight dan Normalized Raw
Weight. Langkah selanjutnya dengan membuat respon teknis terhadap 14 atribut pelayanan yang mendapat prioritas perbaikan. Hasil respon Teknis dapat dilihat pada Tabel 6.

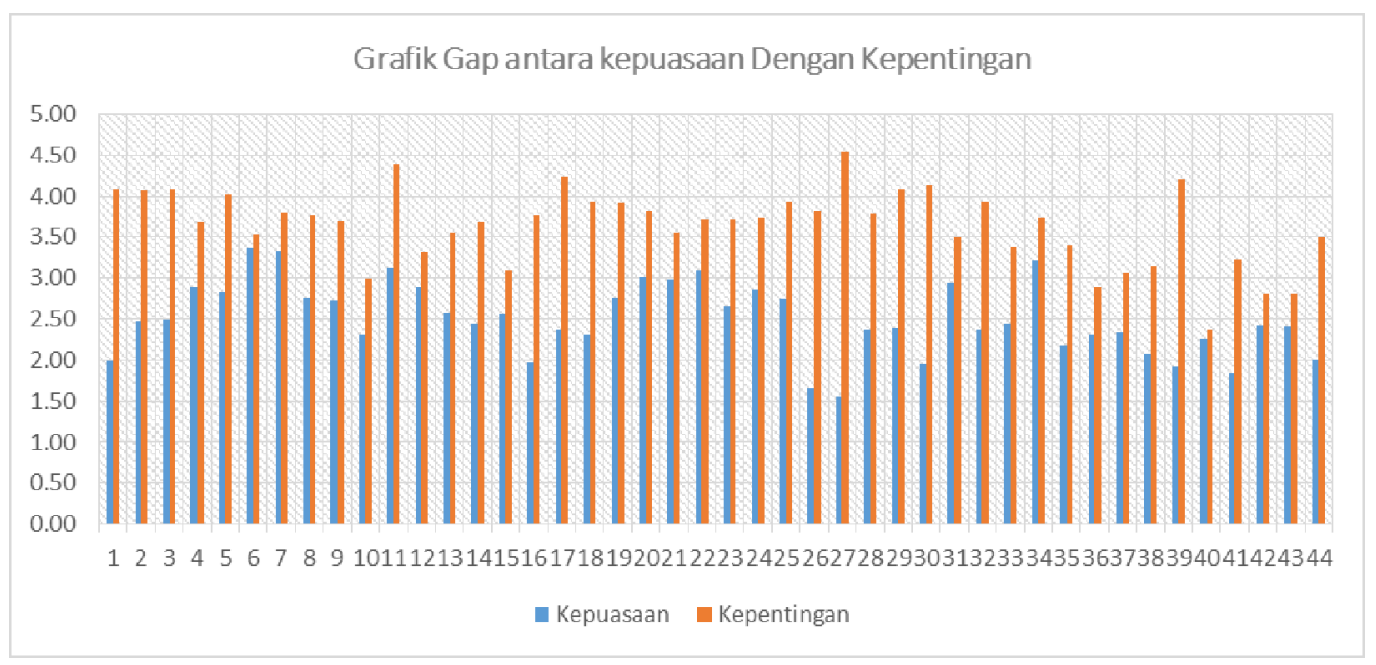

Gambar 4. Grafik Gap Antara Kepuasaan Dengan Kepentingan

Tabel 6. Hasil Respon Teknis

\begin{tabular}{clc}
\hline No & \multicolumn{1}{c}{ Atribut } & Notasi \\
\hline $\mathbf{1}$ & $\begin{array}{l}\text { Perbaikan dan penambahan fasilitas } \\
\text { Kamar mandi dan toilet }\end{array}$ & RT-1 \\
$\mathbf{2}$ & $\begin{array}{l}\text { Memperbaiki fasilitas jalan } \\
\mathbf{3}\end{array}$ & $\begin{array}{l}\text { Memperbaiki dan menambah } \\
\text { kapasitas parkir }\end{array}$ \\
$\mathbf{4}$ & $\begin{array}{l}\text { Memperbaiki dan menambah } \\
\text { kapasitas ruang tunggu }\end{array}$ & RT-3 \\
$\mathbf{5}$ & $\begin{array}{l}\text { Menyediakaan Sirkulasi udara buatan } \\
\text { dalam ruang tunggu }\end{array}$ & RT-4 \\
$\mathbf{6}$ & $\begin{array}{l}\text { Menambah tempat duduk } \\
\text { RT-5 }\end{array}$ & Renambah dan meningkatkan kinerja \\
$\mathbf{8}$ & $\begin{array}{l}\text { petugas } \\
\text { Menungjang kebersihan dalam } \\
\text { terminal }\end{array}$ & RT-7 \\
\hline & RT-8 \\
\hline
\end{tabular}

Sumber: Hasil Pengolahan Data

Setelah didapatkan respon teknis terhadap atribut pelayanan tersebut kemudian dilakukan penyusunan house of quality. Pada tahap selanjutnya membandingkan hubungan masingmasing antara Respon Teknis dengan keinginan pelanggan. Langkah berikut menentukan hubungan antara respon teknis, yang bertujuan untuk mengidentifikasi respon teknis mana saja yang memiliki ketergantungan.

\section{Menentukan Prioritas utama Perbaikan}

Pada analisis ini dilakukan perhitungan terhadap nilai prioritas dari respon teknis terhadap pemenuhan kebutuhan pelanggan, nilai contribution dan nilai Own Performance (OP). Hasil yang didapat nilai Own performance tertinggi 273,75 berada pada respon teknis (RT-2) memperbaiki fasilitas dan nilai own performance terendah 218 ada pada respon teknis (RT-6) menambah tempat duduk. Untuk urutan prioritas berikutnya dapat dilihat pada Tabel 7. Dari hasil tersebut kemudian menggolongkan respon teknis yang terdiri dari:

- Kenyamanan yaitu: memberikan kenyamanan dalam ruang tunggu terhadap cuaca/hawa panas dan hujan.

- Fasilitas sirkulasi udara dalam ruang tunggu

Tabel 7. Hasil Perhitungan Nilai C, NC, KPS x Num, OP dan Target

\begin{tabular}{ccccccc}
\hline $\begin{array}{c}\text { Respon } \\
\text { Teknis }\end{array}$ & Contribution & $\begin{array}{c}\text { Normalized } \\
\text { contribution }\end{array}$ & $\begin{array}{c}\text { Numerical } \\
\text { value }\end{array}$ & $\begin{array}{c}\text { KPS x } \\
\text { Num }\end{array}$ & $\begin{array}{c}\text { Own } \\
\text { Performance } \\
(\text { OP })\end{array}$ & Target \\
\hline RT-1 & 1.573 & 13.261 & 54 & 123.39 & 228.5 & 6 \\
RT-2 & 1.173 & 9.894 & 56 & 153.3 & 273.75 & 1 \\
RT-3 & 1.293 & 10.908 & 56 & 147.24 & 262.928 & 3 \\
\hline
\end{tabular}




\begin{tabular}{llllccc}
\hline RT-4 & 2.068 & 17.441 & 69 & 159.51 & 231.174 & 5 \\
RT-5 & 1.804 & 15.209 & 72 & 181.17 & 251.625 & 4 \\
RT-6 & 1.463 & 12.342 & 45 & 98.1 & 218 & 8 \\
RT-7 & 1.576 & 13.291 & 83 & 225.23 & 271.361 & 2 \\
RT-8 & 0.907 & 7.649 & 28 & 61.69 & 220.321 & 7 \\
\hline
\end{tabular}

Sumber: Hasil Pengolahan Data

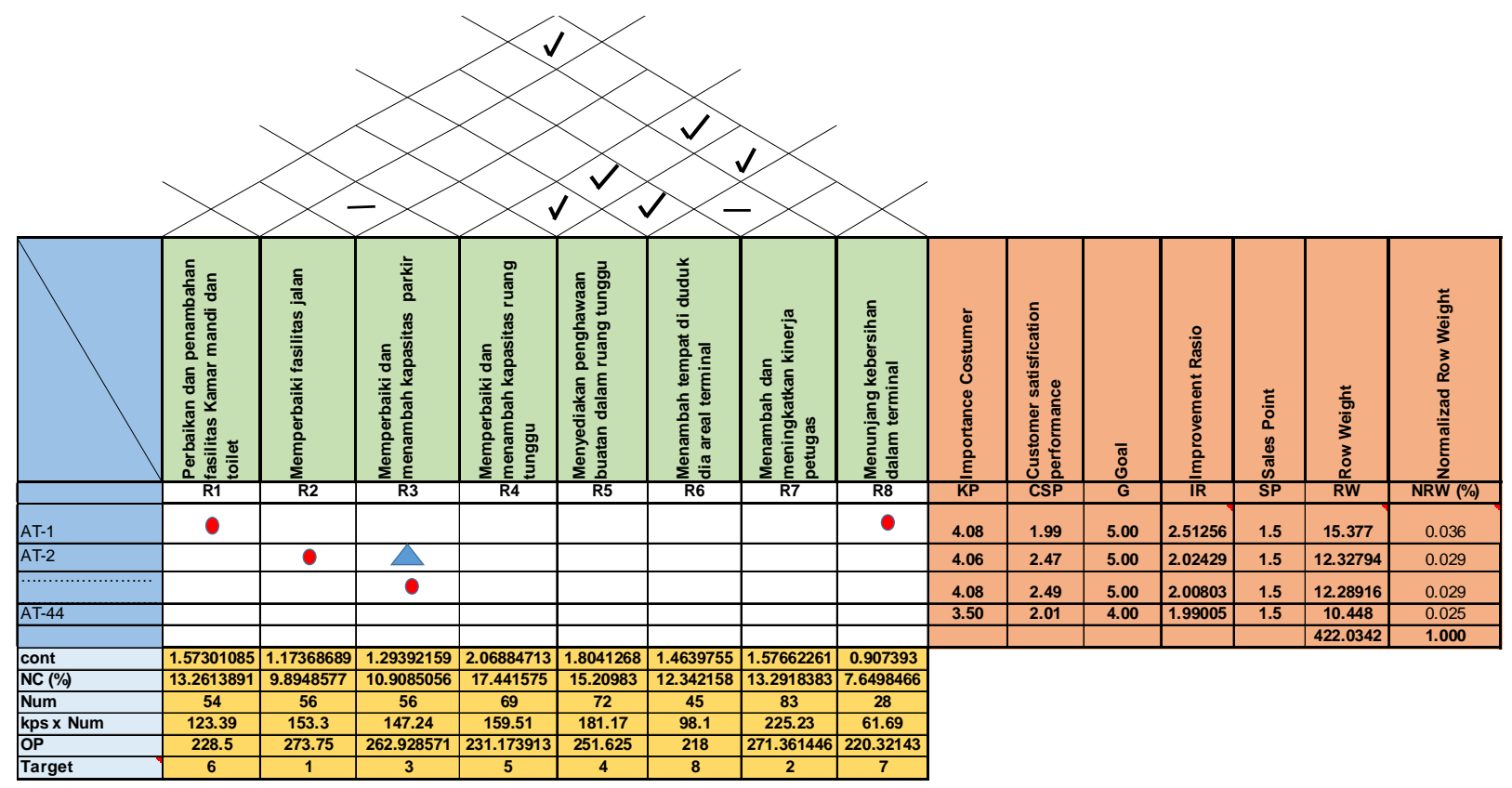

Gambar 5 House of Quality Terminal Becora.

- Kuantitas meliputi: Menambah tempat duduk dalam terminal.

- Petugas meliputi: menambah dan meningkatkan kinerja petugas.

- Fasilitas meliputi: Memperbaiki fasilitas Toilet dan kamar mandi, memperbaiki fasilitas jalan, memperbaiki dan menambah kapasitas parkir, menyediakan fasilitas sampah, memperbaiki dan menambah kapasitas ruang tunggu dan menyediakan fasilitas sirkulasi udara dalam ruang tunggu.

\section{Pembentukan Model Regresi}

Dalam membentuk model regresi linear diambil variabel yang menjadi prioritas perbaikan pada kuadran pertama IPA. Oleh Karena itu model regresi yang ditetapkan, adalah variabel $\mathrm{Y}=$ kualitas, Pelayanan, $X_{1}=$ Kinerja, $X_{2}=$ daya tanggap, $X_{3}=$ Kenyamanan, $X_{4}=$ Kuantitas dan $X_{5}=$ Fasilitas.

\section{Uji Korelasi Dengan Matriks Korelasi}

Sebelum variabel digunakan dalam penentuan model dilakukan Pengujian untuk mengetahui seberapa besar pengaruh suatu variabel terhadap variabel yang lain. Penentuan variabel dilakukan bila antar variabel penjelas $(\mathrm{X})$ menunjukkan pengaruh hubungan yang lemah yaitu $r<0,5$ dan hubungan variabel penjelas $(\mathrm{X})$ dengan variabel respon $(\mathrm{Y})$ menunjukkan hubungan yang kuat yaitu $r>0,5$. Dengan menggunakan metode analisis langkah demi langkah pada Table 7 matriks korelasi terlihat bahwa ada beberapa hubungan antara dua variabel bebas yang memiliki nilai lebih dari persyaratan yang ada yaitu $r>0.5$, sehingga hanya dipakai salah satu peubah bebas yang mempunyai koefisien korelasi lebih besar terhadap (Y). Dari hasil table matriks korelasi terlihat bahwa faktor paling berpengaruh terletak pada variable $\mathrm{X}_{3}$ (kenyamanan) dimana: Pada korelasi $\mathrm{X}_{1}$ dan $\mathrm{X}_{3}$ mempunyai koefisien korelasi $=0.599$ ini berarti $\mathrm{X}_{3}$ mempunyai korelasi yang cukup tinggi terhadap $X_{1}$. Menurut persyaratan yang ada maka hanya dipakai salah satu variabel 
yang nilai korelasinya lebih tinggi terhadap Y yaitu $\mathrm{X}_{3}$. Kemudian dilakukan juga terhadap peubah bebas lainya. Hasil tersebut menunjukkan bahwa Variabel $\mathrm{X}_{3}$ nilai korelasinya lebih tinggi terhadap Y daripada variabel yang lain, dengan mengeliminasi variabel $\mathrm{X}_{1}, \mathrm{X}_{2}, \mathrm{X}_{4}$, dan $\mathrm{X}_{5}$ yaitu variabel kinerja, daya tanggap, kuantitas dan fasilitas, didapatkan model dari pengolahan data sebagai berikut :

$Y=-0,328+0.267 X$

Tabel 8. Variabel yang digunakan untuk model berdasarkan hasil uji korelasi

\begin{tabular}{ccccccc}
\hline \multicolumn{7}{c}{ Matrix Correlations } \\
& $\boldsymbol{Y}$ & $\boldsymbol{X}_{\boldsymbol{I}}$ & $\boldsymbol{X}_{\boldsymbol{2}}$ & $\boldsymbol{X}_{\mathbf{3}}$ & $\boldsymbol{X}_{\mathbf{4}}$ & $\boldsymbol{X}_{5}$ \\
\hline $\boldsymbol{Y}$ & 1.000 & - & - & - & - & - \\
$\boldsymbol{X}_{\boldsymbol{I}}$ & 0.818 & 1.000 & - & - & - & - \\
$\boldsymbol{X}_{\boldsymbol{2}}$ & 0.615 & 0.324 & 1.000 & - & - & - \\
$\boldsymbol{X}_{3}$ & 0.851 & 0.599 & 0.528 & 1.000 & - & - \\
$\boldsymbol{X}_{4}$ & 0.794 & 0.586 & 0.473 & 0.534 & 1.000 & - \\
$\boldsymbol{X}_{\mathbf{5}}$ & 0.834 & 0.536 & 0.423 & 0.717 & 0.598 & 1.000 \\
\hline
\end{tabular}

Sumber: Pengolahan Data

\section{Hubungan Antara Variabel Kenyamanan Dengan Kualitas Pelayanan}

Pada Gambar 6 menunjukkan bahwa nilai konstanta $Y=-0.328+0.276 X_{3}$ masih rendah atau minus yang mengartikan bahwa kualitas pelayanan saat ini masih rendah sehingga apabila dilakukan perbaikan maka setiap kenaikan variabel kenyamanan $\left(\mathrm{X}_{3}\right)$ satu satuan memberikan pengaruh pada kualitas pelayanan sebesar 0,724 atau sebesar $72.4 \%$.

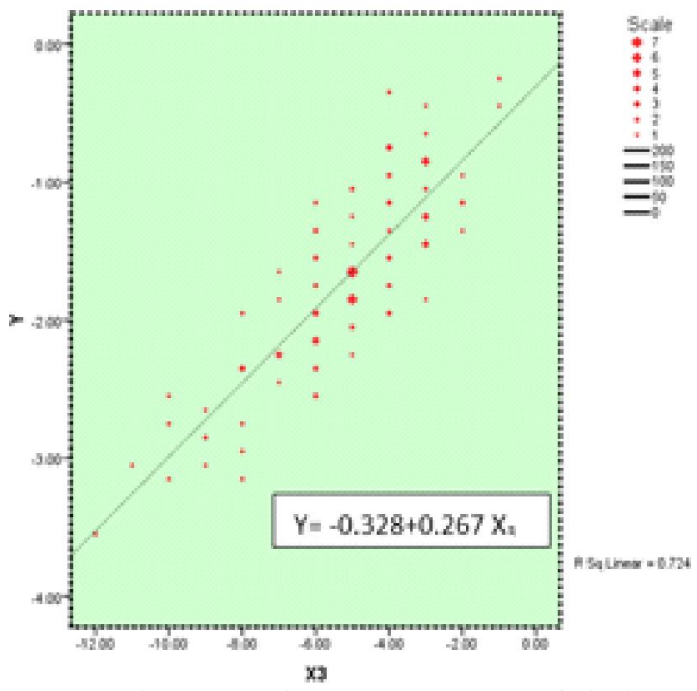

Gambar 6. Hubungan antara variabel Kenyamanan $\left(\mathrm{X}_{3}\right)$ Dan kualitas Pelayanan

\section{KESIMPULAN DAN SARAN}

Berdasarkan hasil analisis dengan metode IPA faktor-faktor yang berpengaruh terhadap kinerja pelayanan terminal Becora terdiri dari 14 atribut yang menjadi prioritas perbaikan. Sedangkan dari hasil analisa dengan metode QFD terdapat 8 respon teknis prioritas perbaikan untuk meningkatkan kinerja pelayanan terminal terhadap pengguna jasa.

Hasil respon teknis memperbaiki fasilitas jalan (RT-2) mempunyai nilai own performace tertinggi 273.75 dan merupakan urutan pertama prioritas perbaikan. Sedangkan Model regresi yang diusulkan adalah : $\mathrm{Y}=-0,328+0.267 \mathrm{X} 3$ Dari model hubungan yang didapatkan $\mathrm{Y}$ merupakan kualitas pelayanan sedangkan $\mathrm{X}_{3}$ merupakan faktor kenyamanan yang merupakan variabel pelayanan.

Hasil analisa menunjukkan bahwa antara kualitas pelayanan dengan variabel kenyamanan menunjukkan hubungan yang signifikan dengan nilai $\mathrm{R}^{2}=0.724$ yang artinya variabel tersebut berpengaruh $72.4 \%$ terhadap kualitas pelayanan terminal. Untuk rekomendasi perbaikan kualitas pelayanan terminal becora pada kajian ini disesuaikan dengan hasil model yang didapatkan sehingga variabel $\left(X_{3}\right)$ kenyamanan menjadi prioritas perbaikan pertama, selanjutnya $\left(\mathrm{X}_{5}\right)$ fasilitas $\left(\mathrm{X}_{1}\right)$ kinerja, $\left(\mathrm{X}_{4}\right)$ kuantitas, $\left(\mathrm{X}_{2}\right)$ daya tanggap.

Hasil kajian tersebut menunjukkan bahwa perlunya upaya-upaya perbaikan yang harus dilakukan untuk meningkatkan kualitas pelayanan agar terjaminnya kepuasaan bagi pengguna jasa terminal Becora. Untuk jangka pendek perbaikan disesuaikan dengan rekomendasi yang ada sedangkan untuk jangka panjang sebaiknya dilakukan redesain pada terminal Becora dengan pertimbangan melalui studi-studi yang lebih mendalam dari aspek ekonomi, aspek sosial dan masyarakat agar terminal Becora dapat dijadikan terminal yang berkonsep multi fungsi terminal.

\section{DAFTAR PUSTAKA}

Dadi Murdadi, 2005, Pemanfaatan terminal angkutan umum regional terkait dengan kebijakan pengembangan wilayah kota pangkalpinang.

Kementrian Pekerjaan Umum,2010, Final Draft Pedoman Pengelolan Terminal Di Kabupaten/Kota. Peserta USDRP 
Keputusan Menteri Perhubungan Nomor 31 tahun 1995 tentang Terminal Transportasi Jalan.

Purba, Djamahaen, 2008 Analisis Prioritas faktorfaktor yang Mempengaruhi Efektivitas Fungsi Terminal Sarantama (Study Kasus Terminal Sarantama Kota Pematang Siantar).

Rahman, R, 2009, Evaluasi Sistem Pelayanan Pesawat dengan Tarif yang Berbeda Terhadap Tingkat Kepuasan Penumpang. Jurnal Mektek Tahun XI No. 2 Mei 2009

Sedayau, Agung, 2013, Pemodelan Pelayanan Terminal Penumpang Transportasi Berbasis Kepuasaan Pengguna Jasa.

Sedayu A, (2014) Target Peningkatan Pelayanan Terminal Purwosari Kediri dengan Metode IPA dan QFD, Eco Rekayasa vol.10/No1/ Maret 2014

Suryaningrat, I.B, 2010, Aplikasi Metode Quality function Development (QFD) untuk peningkatan kualitas produk mie jagung. jurnal Agrotek Vol. 4 No 1,2010 8-17

Tamin, Ofyar, Z, 2000, Perencanaan dan pemodelan transportasi. Edisi kedua. Penerbit ITB Bandung. ISBN 979-9299-10-1. 2000 